\title{
Westward Ecological Feminist Literary Criticism and Its Enlightenment
}

\author{
Haiou Pan \\ College of Foreign Languages, Liaoning University of Traditional Chinese Medicine, Shenyang, 110847, \\ China
}

30662238@qq.com

Keywords: westward ecological feminist literary criticism; theoretical basis; enlightenment

\begin{abstract}
Western ecological feminist literary criticism is a product of the organic combination of feminist criticism and ecology criticism. It uses a unique dual perspective of nature and women to explore the interrelationships between literature and gender, class, race, and nature. Based on the theory of westward ecological feminist literary criticism, this paper proposes the enlightenment of westward ecological feminist literary criticism: the thorough dissolution of binary opposition between man and nature, making literary studies move toward a broader ecological perspective, and constructing the diversified literary criticism idea of cross - interaction. The literary criticism concept advocates the new development perspectives of the close connection between women and the environment, and the development of the Eco-feminist literary criticism in the romantic view of nature. The purpose of the research is to realize the goals of the Eco-feminist literary criticism of "natural harmony, equality between men and women" and realize the harmonious development of man and nature.
\end{abstract}

\section{Introduction}

Feminist literature refers to female gender-based subjectivity, and uses female language and culture to create. The content expressed is related to the unique experience and feelings of female lives. The text shows the unique quality and vitality of female discourse. [1]. Feminist literary criticism has greater impact on literary standards than any other critical theory and is one of the most innovative forces in modern critical theory. Eco-feminist criticism is the product of the organic combination of feminist criticism and eco-criticism. The feminists advocated the overthrow of the patriarchal rule, which enabled women to finally advance to the status of independence and independence. Feminist literary criticism advocates subverting the patriarchal culture and eliminating the male centered culture. It is a question of traditional values and literary criticism and a branch of post-structuralist criticism. Eco-criticismmainly studies the relationship between literature and nature, inherits the tradition of natural literature, and has its own characteristics. It mainly reviews literary works and advocates reading literary works from the ecological point of view, so that humans can enhance their awareness of environmental protection and their sense of urgency.

The Eco-feminist literary criticism, literary criticism from the dual perspectives of environment and gender, shows that "nature" and "female" are moving from the forgotten corner to the front desk. The change from "absence" to "presence" indicates that the tentacles of literary studies have not only reached out to the other half of human society but, more importantly, they have begun to reach beyond the human society. Eco-criticismliterary criticism not only focuses on superficial women and nature, but also focuses on the unreasonable ways of thinking of people under the influence of the anthropocentrism and male centralism. Through this research, we will guide people to establish correct, comprehensive, and effective concept of existence and women; review ecological evolution, female values, and the future development of people; call for people to care for women and nature, and ultimately make the natural environment , men and women, live in harmony and coordinate development. 


\section{Generation and Development on Westward Ecological Feminist Literary Criticism}

Western the Eco-feminist literary criticism originated in France and developed rapidly in the United States, Britain, Germany and other Western countries. Since the 1960s, the increasingly serious ecological crisis has swept the world. Faced with the ever-increasing ecological crisis, economic, political and cultural fields have made different responses. In the field of sociology, emerging disciplines such as environmental ethics, deep ecology, and the Eco-feminist are competing to discuss the root causes of environmental deterioration and ecological crisis and establish a sustainable development concept of survival in order to establish a harmonious relationship between man and nature. Provide ethical and conceptual foundations. In the 1990s, some the Eco-feminists in the West began to examine and study environmental issues and gender issues from the perspective of literature. the Eco-feminist began to permeate the literary world in the West. In the new century, Western the Eco-feminist literary criticism has further expanded the field of literary studies, further literary studies have shifted outwards, and extended the reach of literary studies to the natural world beyond human society and has long been forgotten by humans. The purpose of the criticism of the interrelationship between literature and the natural environment is to awaken people' $s$ awareness of ecological protection through literary studies and achieve a harmonious development of man and nature, thereby establishing a society in which people and nature live in harmony, in species equality, and in ecological balance. The sustainable development of human economy and society.

The Eco-feminist thoughts were introduced into China from the mid-1990s. They mainly summarized and promoted the viewpoints and representative works of the Eco-feminist representatives, and almost all explored ecological feminism from the perspective of philosophy. Until the 21st century, the research and application of ecological feminist literary criticism began in China. Judging from the current three aspects of journal articles, master papers, and humanities and social sciences topics, not only do the theories have a certain breakthrough, but also there are examples of the combination of theory and literary works; not only the work of female authors is interpreted There are also interpretations of male writer's works. All of these prove that the Eco-feminist literary criticism is a viable and energetic critical theory, and it is at the forefront of the domestic academic field and is gradually setting off a new wave of literary criticism.

\section{Theoretical Basis on Westward Ecological Feminist Literary Criticism}

Theory links the concept or principle of actual deduction in an activity field, or through a long-term observation and summary of things, through the extraction of key factors in the process of a certain thing, thus forming a simplified description of the evolution process of things. model. There are many basic theories of Western ecological feminist literary criticism. The following generations are the most representative:

(1) Marxist feminist critical theory. Marxist feminist criticism, based on the criticism and suspicion of Marxist female theory in many aspects, uses gender theory as a breakthrough point, and inputs fresh blood for contemporary critical areas. The discussion of gender equality and difference is reflected in the practice of criticism, advocating female traditions, emphasizing female experience, female unique imagination and understanding, and calling for the establishment of female literary history and female aesthetics. In the formation and development of Marxist feminist criticism, some adhered to the Marxist tradition, some modified Marxist theory, inherited and promoted the spirit of Marxist criticism and skepticism, and shaken the cultural tradition centering on patriarchal rights and female liberation. Sports made a contribution. Marxist female theory provides a theoretical basis for feminist criticism. The multiple criticism methods such as gender and ethnicity in feminist criticism have enriched and developed the Marxist view of women and are the logical extension of Marxist theory.

(2) Ecological feminist theory. the Eco-feminist is the product of the combination of female liberation movement and ecological movement, and is an important school of feminist research and 
ecological philosophy. From the point of view of gender, we have entered the ecological problem, pointing out that the rule of male power and the rule of human beings are rooted in the understanding based on the logic of patriarchy and further in-depth criticism [2]. the Eco-feminists believe that the definition of women and nature in the patriarchal society determines the subordinate status of women, and there is an inevitable link between oppression of women and the destruction of nature. Women are the greatest victims of environmental degradation. the Eco-feminist theory can be said to be natural feminism, inheriting past theories and opening up new areas of research. In addition to pursuing social reforms, this political movement has also been expanded into the field of knowledge. The differences between female nature and male nature have been studied from various angles, and the roles of women and women have been explored. The patriarchal system that causes discrimination against women and oppresses women has been carried out. Comprehensive and in-depth analysis and criticism.

(3) The theory of female criticism [3,4]. Elaine Showalter is the creator of this important theory and the most influential critic of contemporary western feminist criticism. Elaine Showalter believes that although there are no fixed feminine features or female imaginations, the creation of women and men is very different. Therefore, feminine literature has unique attributes and has a tradition of self-integration. It needs to discover and write female own literature. Tradition. Because female roles are assigned and limited by men, female writing tradition has always been artificially suppressed and buried by the patriarchal culture. The theory of feminist criticism mainly includes two aspects. First, women read, change from an acknowledgment reader to a reader of resistance, and remove the masculine consciousness rooted in female hearts. Second, female writing, female writing is based on the female experience. The characteristics and the formation process of female subjects, and the establishment of female language systems with literary writing, have become an important task for feminist critics in the new era.

\section{Enlightenment on Westward Ecological Feminist Literary Criticism}

Western the Eco-feminist literary criticism combines feminist criticism and ecological theory in two different fields. It presents people with a new perspective of thinking and a reading perspective, and is favored by literary critics. It has important enlightening effects on female liberation, literary creation, environmental protection and human development:

(1) Completely dissolve the binary opposition between man and nature. Western civilization uses moral dualism to turn natural tools into a means of serving humanity. Humanity is seen as the only real subject. The natural world and the ecosystem are insignificant. The environment becomes a natural material base for human survival. This kind of natural comprehensiveness Devaluation and denial are deeply rooted in the mainstream view of human beings and the nature is negatively constructed [5]. This kind of polar exclusionary bipolar effect leads to an alienated interpretation of human identity. American scholar Kircher points out the danger of over-combining women with nature, which is very easy to produce binary opposition. While associating women with nature, Williams seeks to associate nature with culture, engage women in culture, and try to construct a synthesis of nature and culture. Human beings protect nature, which is to protect themselves. To treat the natural environment well is to be kind to yourself. To consider the long-term survival and development of mankind, it is necessary to establish the ecological ethic concept of harmony between man and nature.

(2) To make literary studies move toward a broader ecology. Eco-criticism places literary criticism in the the Earth ecosphere context. and it is full of vigor and vitality with its unique ecological criticism and its ultimate concern for the survival prospects of all human beings [6]. Broadness, interdisciplinary, and openness, combined with existing literary theories, make literary studies a broader perspective of ecology. The re-exploration and restoration of female literary works has become an urgent task for the Eco-feminist literary scholars. When women use a unique perspective to interpret nature and men, culture, or deeper values, they can eliminate the narrowness and unity of male perspective. Environmental justice supports the sacred nature of the Mother Earth, ecological solidarity and the interdependence of species, as well as the right to get rid of ecological 
destruction, to a certain extent, to enrich the scope of the text of literary studies. A large number of male classical texts have re-entered the field of vision of the Eco-feminist literary critics. They have been redefined and interpreted to give a new meaning to literary classics from a completely new perspective.

(3) "Natural harmony, equality between men and women" is the goal of feminist literary criticism. The British female writer Adeline Virginia Woolf, in the novel "Mrs. Dalloway", revealed this social reality [7]: Women cannot accept formal education, cannot go out to work, become subjects of dominance and repression, and are in a state of "aphasia". . The author points out an independent road for all the oppressed women, and regards the pursuit of gender harmony as the ultimate ideal, advocates that both genders live together in harmony, and work together to create a truly free and equal human society. In the novel "A woman must have money and a room of her own if she is to write fiction", Woolf compares female own values with the values of women set by men, and considers that female values are products of nature rather than culture. The pursuit of female liberation, the development of female self-consciousness, and the construction of an ideal of a complete gender equality and a harmonious symbiotic world. Men will no longer regard women as "second sex", replacing contradictions, confrontations and conflicts and enhancing dialogue, complementary and understanding.

(4) Construct cross-interactive and pluralistic literary criticism. the Eco-feminist criticism is the intersection of Eco-criticism and feminist criticism. Western feminist literary criticism is in a multipolar historical development stage, especially in the new historical period, pluralistic criticism methods, diverse social environment, and multiple competitions. The pattern, cultural paradigm and human consciousness are gradually increasing, requiring literary criticism to pay more attention to the process and significance of criticism. It is necessary not only to promote the value and breadth of literary criticism, but also to pay attention to the comparative literature [8]. Learning from the Western ecological sciences, ecological philosophy, ecological ethics and their corresponding rational thinking and logical knowledge, constructing a cross-interactive and pluralistic literary criticism concept is an important goal of Eco-feminist literary criticism. In the process of cultural theory that emphasizes integrity, harmony, interactivity, and diversity, Eco-feminist literature and criticism will play an important and unique theoretical role [9].

(5) A new development perspective that advocates a close connection between women and environmental protection. the Eco-feminist literary criticism, from the perspective of feminism and deep ecology theory, criticizes the male patriarchal system, realizes human development through environmental protection, advocates the overthrow of the rule of nature and women, and also overthrows all races related to it. Discrimination, discrimination at the social level, age discrimination, and homosexuality discrimination make the natural ecology and women get balanced and emancipated. The theory of the Eco-feminist urges people to form a new habit of thinking and lifestyle, thus forming a new and harmonious development model. In addition, not all feminist theories are opposed to men. Men are also the victims of the environment. Environmental issues should be shared together. The ideal ecological governance model requires the integration of both men and female wisdom and temperament. From the traditional male-dominated ecological governance model to the harmonious governance model of both men and women, it is the development path of ecological civilization construction.

(6) The development of the Eco-feminist literary criticism from the romantic view of nature. Romanticism attaches great importance to nature, emphasizing the nature of human nature represented by nature. This "nature" includes both the nature of human existence and the nature of human nature. The longing for nature and the praising of natural humanity are the subject and expression object of romanticism literature. The process of moving toward nature is also a process of awakening women and revival of their lives. Both physical and spiritual gains are pleasing and detached [10]. On the one hand, the Eco-feminist literary criticism has increased the dimension of nature within the category of feminism, adhered to the romantic organic concept of nature, criticized the theory of the Anthropocentrism, broadened the horizon of feminist research, and also opened up natural and The theme of feminine relations; on the other hand, the Eco-feminist literary 
criticism has evolved towards the romantic outlook on nature, surpassing the romanticism's advocacy and admiration of natural static, explicitly advocates the protection of nature, emphasizing the harmony between men and women and nature. The harmony, therefore, has a strong practical purpose.

\section{Conclusion}

The rise of the Eco-feminist literary criticism has complex ideological origins and multiple social backgrounds. It is based on the ecological feminist critique and uses a unique dual perspective of nature and women to explore literature and gender, class, race and nature. The interrelationships between the two are moving towards the development of international diversification, providing novel positions, perspectives, and viewpoints for criticisms such as literary criticism, cultural criticism, and ideology. Eco-feminist criticism puts literary criticism under the context of gender discrimination and ecological crisis. From its ecological perspective and female perspective, it reflects the ultimate concern for the environmental crisis and the survival prospects of all human beings. Its broadness, openness, and cross- Literary studies have injected vitality and vitality, provided new perspectives for criticism, and enriched and developed literary criticism theories.

\section{References}

[1] Y. Ma, "Feminist literary criticism in foreign literature works," Journal of Jiamusi College of Education, vol. 31, no. 5, pp. 85-86, 2014.

[2] S. J. Pan, "On the three basic theories of ecological criticism," Literature Education, vol. 12, no. 12, pp. 26-27, 2016.

[3] Z. Y. Zhang, J. Wang, "Showalter and Western Feminist Literary Criticism," Journal of Kaifeng Institute of Education, vol. 34, no. 3, pp. 11-12, 2014.

[4] S. J. Pan, "Showalter and the Western Feminist Criticism Theory," Mountain Flowers, vol. 50, no. 4, pp. 154-155, 2009.

[5] Y. H. He, "The Discursive strategy of Eco-feminist literary criticism," Master's degree of Inner Mongolia Normal University, 2015.

[6] M. L. Chen, "Prospects for Western Literary Theory in the New Century: Cultural Studies and Eco-criticism," Academic Exchange, vol. 19, no. 4, pp. 114-119, 2003.

[7] L. L. Wang, "Nature, equality and harmony: Interpretation of the ecological feminist consciousness of Mrs. Dalloway," Journal of Mudanjiang College of Education, vol. 29, no. 1, pp. 11-12, 2011.

[8] X. W. Mo, "On the pluralistic criticism of foreign literature," Flying Apsaras, vol. 50, no. 18, pp. 27-28, 2009.

[9] M. L. Chen, "A Discussion of Ecofeminist Lite Criticism," Qilu Journal, vol. 76, no. 6, pp. 108-111, 2006.

[10] S. Yuan, "Brief analysis of ecofeminist literary criticism: Take 'Mrs. Chatellet's lover' as an example," Journal of Lvliang University, vol. 4, no. 3, pp. 17-19, 2014. 